\title{
Changes in ambient temperature increase hospital outpatient visits for allergic rhinitis in Xinxiang, China
}

Jianhui Gao ${ }^{1}$, Mengxue Lu', Yinzhen Sun ${ }^{1,2}$, Jingyao Wang ${ }^{1}$, Zhen An ${ }^{1,2}$, Yue Liư ${ }^{3}$ Juan Li ${ }^{1,2}$, Zheng Jia ${ }^{4}$, Weidong $\mathrm{Wu}^{1,2}$ and Jie Song ${ }^{1,2^{*}}$

\begin{abstract}
Background: The effect of ambient temperature on allergic rhinitis (AR) remains unclear. Accordingly, this study aimed to explore the relationship between ambient temperature and the risk of AR outpatients in Xinxiang, China.

Method: Daily data of outpatients for AR, meteorological conditions, and ambient air pollution in Xinxiang, China were collected from 2015 to 2018. The lag-exposure-response relationship between daily mean temperature and the number of hospital outpatient visits for AR was analyzed by distributed lag non-linear model (DLNM). Humidity, long-time trends, day of the week, public holidays, and air pollutants including sulfur dioxide $\left(\mathrm{SO}_{2}\right)$, and nitrogen dioxide $\left(\mathrm{NO}_{2}\right)$ were controlled as covariates simultaneously.

Results: A total of 14,965 AR outpatient records were collected. The relationship between ambient temperature and AR outpatients was generally M-shaped. There was a higher risk of AR outpatient when the temperature was 1.6-9.3 ${ }^{\circ} \mathrm{C}$, at a lag of $0-7$ days. Additionally, the positive association became significant when the temperature rose to $23.5-28.5^{\circ} \mathrm{C}$, at lag $0-3$ days. The effects were strongest at the 25 th $\left(7^{\circ} \mathrm{C}\right)$ percentile, at lag of $0-7$ days (RR: 1.32 , $95 \%$ confidence intervals (Cl): $1.05-1.67)$, and at the 75 th $\left(25^{\circ} \mathrm{C}\right)$ percentile at a lag of $0-3$ days (RR: $1.15,95 \% \mathrm{Cl}$ : 1.02-1.29), respectively. Furthermore, men were more sensitive to temperature changes than women, and the younger groups appeared to be more influenced.

Conclusions: Both mild cold and mild hot temperatures may significantly increase the risk of AR outpatients in Xinxiang, China. These findings could have important public health implications for the occurrence and prevention of $A R$.
\end{abstract}

Keywords: Ambient temperature, Allergic rhinitis, Outpatient, Distributed lag non-linear model

\section{Introduction}

Allergic rhinitis (AR) is triggered by a spectrum of environmental allergens and is considered an immunoglobulin E (IgE) mediated type 1 hypersensitivity illnesses [1]. AR is typically classified according to the four common

\footnotetext{
*Correspondence: songjie231@126.com

'Xinxiang Medical University, Xinxiang 453003, China

${ }^{2}$ Henan International Collaborative Laboratory for Health Effects and Intervention of Air Pollution, Xinxiang 453003, China

Full list of author information is available at the end of the article
}

nasal symptoms: sneezing, itching, rhinorrhea, and nasal congestion. In addition, AR may result in itchy upper jaw, coughing, and swollen watery eyes [2]. Furthermore, AR may impair cognitive function and sleep quality, causing fatigue and irritability. Other negative health conditions concluding hypertension, sinusitis, asthma, and otitis media are also commonly caused by AR $[3,4]$. Therefore, AR can significantly affect patient quality of life, and contribute to a decline in school performance, work productivity, and social life [3, 5], especially during

(c) The Author(s). 2021 Open Access This article is licensed under a Creative Commons Attribution 4.0 International License, which permits use, sharing, adaptation, distribution and reproduction in any medium or format, as long as you give appropriate credit to the original author(s) and the source, provide a link to the Creative Commons licence, and indicate if changes were made. The images or other third party material in this article are included in the article's Creative Commons licence, unless indicated otherwise in a credit line to the material. If material is not included in the article's Creative Commons licence and your intended use is not permitted by statutory regulation or exceeds the permitted use, you will need to obtain permission directly from the copyright holder. To view a copy of this licence, visit http://creativecommons.org/licenses/by/4.0/. The Creative Commons Public Domain Dedication waiver (http://creativecommons.org/publicdomain/zero/1.0/) applies to the data made available in this article, unless otherwise stated in a credit line to the data. 
the peak pollen season [1]. AR morbidity has soared worldwide in recent decades [6]. Previous studies have demonstrated that the prevalence of AR varies between different countries. However, more than $20 \%$ of the population is affected by AR worldwide [7]. In some countries, more than $50 \%$ of citizens were reported to have AR [8-10]. Estimates showed that the medical costs associated with loss of work efficiency caused by AR was US\$ 1664 per patient, per year [11]. Consequently, the overall medical and economic burdens associated with AR are enormous.

Increasing evidence have revealed that both environmental and genetic factors play important roles in the etiology of allergic diseases, including $\mathrm{AR}[4,12,13]$. Ambient temperature is a major environmental factor, and reports have frequently related it to health outcomes with significant lag effects such as global overall mortality, respiratory diseases, cardiovascular diseases, and cerebrovascular diseases [14-18]. Moreover, several studies have documented that high temperatures were related to respiratory problems [19]. However, the evidence for this relationship is scarce and inconsistent. Population studies in the Pacific Rim showed that the AR prevalence was positively correlated with mild hoter temperatures [20], whereas in the northern hemisphere, individuals with AR often had increased respiratory symptoms due to frequent cold air exposure [21]. Recent evidence suggests that cold weather may aggravate symptoms, especially in patients with certain underlying respiratory diseases [22]. A high incidence of respiratory symptoms was also reported in cold indoor environments [23]. Another population-based study demonstrated that in adults with certain respiratory illnesses, increased symptoms occurred in cold environments and were more pronounced in patients with rhinitis [24].

The development of climate change and global warming due to increased atmospheric carbon dioxide $\left(\mathrm{CO}_{2}\right)$ levels has been widely accepted over the past decades. Due to its very large population, even a minor temperature increase could potentially cause huge health losses in China. However, the potential effect of ambient temperatures on AR has not been directly examined in the Chinese population. Consequently, we performed a time-series study to explore the lag-exposure-response relationship between the prevalence of AR-related outpatient visits and ambient temperature.

\section{Methods}

The population of Xinxiang, China $\left(35.18^{\prime} \mathrm{N}, 113.52^{\prime} \mathrm{E}\right.$; area $8269 \mathrm{~km}^{2}$ ) was approximately 5.67 million at the end of 2014. The city is located in north of Henan province, on the north side of the Yellow River. Our research area was limited to the four traditional urban districts $\left(422 \mathrm{~km}^{2}\right)$. Xinxiang has a typical temperate continental monsoon climate, with prevailing northeasterly winds.

\section{Hospital outpatient data}

Six hospitals are distributed throughout the urban districts of Xinxiang, and hospital-specific geographic information was described in our previous research [25]. The study excluded one military hospital and hospital lacking an electronic information system from the study. The four remaining hospitals (Xinxiang Central Hospital, Xinxiang First People's Hospital, Xinxiang Second People's Hospital, and the Third Affiliated Hospital of Xinxiang Medical University) were included. Computerized records of ARrelated visits from January 1, 2015 to December 31, 2018 were retrieved from the health information system of each hospital. Subsequently, the data were cleaned and quality controlled as described in our previous study [26]. The number of daily AR visits was summarized based on the J30 code as determined by the International Classification of Diseases (10th revision) for AR.

\section{Ambient temperature and air pollutants data}

Daily meteorological parameters, including relative humidity, maximum, minimum, and mean daily temperatures in Xinxiang from January 1, 2015 to December 31, 2018 were collected from the China Meteorological Data Sharing Service System (http//106.37.208.235.20035/). Additionally, daily mean concentrations of nitrogen dioxide $\left(\mathrm{NO}_{2}\right)$ and Sulfur dioxide $\left(\mathrm{SO}_{2}\right)$ pollutants were measured at four fixed-site stations administrated by the Xinxiang Ministry of Ecology and Environment.

\section{Statistical analysis}

Due to lag effects and the non-linearity of correlations between temperature and specific diseases reported in previous studies [27-30], a distributed lag non-linear model (DLNM) was applied in this study to examine the association between AR outpatient visits and ambient temperature [31]. The DLNM models combines prediction and lag effect in a bi-dimensional matrix (so called cross-basis), and is effective for estimating prediction across a possible maximum lag period.

A generalized additive model was adopted to link the outcome (daily AR outpatient visits) and exposure (daily mean ambient temperature). Additionally, several covariates were incorporated to control for potential confounding effects as previously described [32]. Covariates included (1) unmeasured long-term and seasonal trends in AR incidence, controlled by a natural cubic smooth function with a degree of freedom (df) of 7 per year; (2) relative humidity; (3) day of the week; (4) holidays, and (5) daily mean concentrations of $\mathrm{NO}_{2}$ and $\mathrm{SO}_{2}$ (previously reported as potential hazard factors for AR) [25]. To optimize the model, we calculated the Akaike 
information criterion (AIC) value and selected the minimal structure as the best model. And in order to check the stability of our model, we selected alternative $\mathrm{df}$ for time space with $4-10$ per year.

The 1st $\left(-2{ }^{\circ} \mathrm{C}\right)$, 25th $\left(7^{\circ} \mathrm{C}\right)$, 75 th $\left(25^{\circ} \mathrm{C}\right)$, and 99th $\left(32^{\circ} \mathrm{C}\right)$ daily mean temperature percentiles relative to the median temperature were calculated for the relative risks (RR) and 95\% confidence intervals (CIs) of the AR outpatient visits at cumulative lag effects from 0 to 28 days, respectively. These measurements were applied to analyze the effects of cold, mild cold, mild hot, and hot temperatures on AR outpatient visits. Moreover, we conducted sex and age ( $<15$ years, $15-64$ years, and $\geq 65$ years) group stratification analyses to determine their effects on the risk of AR outpatient visits. The statistical significance of differences between effect estimates of the strata by calculating the $95 \%$ confidence intervals $(\mathrm{CI})$ as $\left(\hat{Q}_{1}-\hat{Q}_{2}\right) \pm 1.96 \sqrt{\left(\mathrm{SE}_{1}\right)^{2}+\left(\mathrm{SE}_{2}\right)^{2}}$, where $\hat{Q}_{1}$ and $\hat{Q}_{2}$ are the estimates for two categories, and $\mathrm{SE}_{1}$ and $S \hat{\mathrm{E}}_{2}$ are their respective standard errors [33].

All statistical analyses were completed by DLNM and MGCV packages in R software (Version 3.3.3). A $p$ value of $<0.05$ were considered statistically significant.

\section{Results}

Between January 1, 2015 and December 31, 2018, there were 14,965 hospital outpatient visits due to AR in Xinxiang, China. A total of 7912 male and 7050 female outpatients ( 3 records missing) were collected (Table 1). Of the total AR outpatients, 2159 were less than 15 years of age, 11,945 were 15-64 years, and 861 were at least 65

Table 1 Daily hospital outpatients for allergic rhinitis, meteorological and air pollution factors in Xinxiang, 2015-2018

\begin{tabular}{|c|c|c|c|c|c|c|}
\hline \multirow{2}{*}{$\begin{array}{l}\text { No. of daily } \\
\text { outpatients for allergic } \\
\text { rhinitis (J30) }\end{array}$} & Mean (SD) & P1 & P25 & P50 & P75 & P99 \\
\hline & $11(8)$ & 0 & 5 & 8 & 13 & 40 \\
\hline \multicolumn{7}{|l|}{ Sex } \\
\hline Female & $5(5)$ & 0 & 2 & 4 & 7 & 19 \\
\hline Male & $6(5)$ & 0 & 2 & 4 & 7 & 23 \\
\hline \multicolumn{7}{|l|}{ Age } \\
\hline$<15$ years & $2(2)$ & 0 & 0 & 1 & 2 & 9 \\
\hline $15-64$ years & $9(7)$ & 0 & 4 & 7 & 10 & 33 \\
\hline$\geq 65$ years & $1(1)$ & 0 & 0 & 0 & 1 & 3 \\
\hline \multicolumn{7}{|l|}{ Meteorological measures } \\
\hline Mean temperature $\left({ }^{\circ} \mathrm{C}\right)$ & $16(10)$ & -2 & 7 & 17 & 25 & 32 \\
\hline Humidity (\%) & $60(17)$ & 22 & 48 & 62 & 74 & 93 \\
\hline \multicolumn{7}{|c|}{ Air pollutant concentration $(\mu \mathrm{g} / \mathrm{m} 3)$} \\
\hline $\mathrm{NO}_{2}$ & $48(21)$ & 16 & 32 & 45 & 61 & 111 \\
\hline $\mathrm{SO}_{2}$ & $33(25)$ & 6 & 16 & 26 & 42 & 122 \\
\hline
\end{tabular}

P75 25 th percentile, $P 99$ 99th percentile; years of age. The annual mean temperature during this time period was $16^{\circ} \mathrm{C}$, and the temperature ranged from $-6.1^{\circ} \mathrm{C}$ to $34.6{ }^{\circ} \mathrm{C}$. The annual mean concentrations of $\mathrm{NO}_{2}$ and $\mathrm{SO}_{2}$ were $48.0 \mu \mathrm{g} / \mathrm{m}^{3}$ and $33.0 \mu \mathrm{g} / \mathrm{m}^{3}$, respectively.

Table 2 presents the estimated RRs of daily mean temperatures on AR outpatient visits, adjusted for confounding factors, including long-time trends, day of the week, relative humidity, and ambient concentrations of $\mathrm{NO}_{2}$ and $\mathrm{SO}_{2}$ at the 1st, 25th, 75th, and 99th temperature percentiles relative to the median temperature $\left(17^{\circ} \mathrm{C}\right)$ over different lag times. Non-significant associations between cold temperatures $\left(-2{ }^{\circ} \mathrm{C}\right.$, 1st percentile) and AR outpatient visits were observed for all lag times. The heat temperature $\left(32^{\circ} \mathrm{C}\right.$, 99th percentile) had a negative effect on AR outpatient at a lag of 0-14 days, 0-21 days, and 028 days. The results show that either mild cold $\left(7^{\circ} \mathrm{C}\right.$, 25th percentile) or mild hot $\left(25^{\circ} \mathrm{C}\right.$, 75 th percentile) temperatures could increase the risk for AR. Of note, mild cold temperatures had slightly longer lag times (lag 0-6 days, lag 0-7 days) and the mild hot temperatures had slightly shorter lag times (lag $0-2$ days, lag $0-3$ days).

Figure 1 depicts the lag pattern of the temperature's effect on AR using a series lag structures. Mild cold temperatures from $1.6^{\circ} \mathrm{C}$ to $9.3^{\circ} \mathrm{C}$ may increase AR prevalence at a lag of 0-7 days (Fig. 1), and mild hot temperatures between $23.5^{\circ} \mathrm{C}$ and $28.5^{\circ} \mathrm{C}$ may increase the AR risk at a lag of $0-3$ days (Fig. 1).

The exposure-response curves of daily mean temperature on AR hospital outpatients at a lag of $0-7$ and $0-3$ days stratified by sex are presented in Fig. 2 . The results showed that men were more susceptible than women to temperature, including mild cold temperatures at a lag of 0-7 days, and mild hot temperatures at a lag of 0-3 days. The age-stratified results showed that the young group $(<15$ years of age) was sensitive to mild cold temperatures at a lag of $0-7$ days (Fig. 3).

The sensitivity analysis results proved that the acute effects did not change substantially with the adjustment of smoothness of time using alternative $\mathrm{df}$ from 4 to 10 per year (Supplement Fig. 1). That suggesting our models are robust and probably not attributable to chance.

\section{Discussion}

In this study, we observed that both mild cold and mild hot temperatures were significantly associated with an increased risk of AR in Xinxiang, China. An "M"-shaped exposure-response curve for AR and daily temperature was observed. Males and the younger group $(<15$ years of age) may be more sensitive to ambient temperature. To our knowledge, this was one of the few studies to directly investigate the relationship between ambient 
Table 2 Relative risks of allergic rhinitis associated with daily mean temperature among selected cutoff points

\begin{tabular}{lllll}
\hline $\begin{array}{l}\text { Lag } \\
\text { effects } \\
\text { (days) }\end{array}$ & $\begin{array}{l}\text { 1st percentile relative to } \\
\text { median temperature RR } \mathbf{( 9 5 \%} \\
\text { Cl) }\end{array}$ & $\begin{array}{l}\text { 25th percentile relative to } \\
\text { median temperature RR } \mathbf{9 5 \%} \\
\text { Cl) }\end{array}$ & $\begin{array}{l}\text { 75th percentile relative to } \\
\text { median temperature RR (95\% } \\
\text { Cl) }\end{array}$ & $\begin{array}{l}\text { 99th percentile relative to } \\
\text { median temperature RR (95\% } \\
\text { Cl) }\end{array}$ \\
\hline Lag 0 & $0.98(0.75-1.27)$ & $1.03(0.89-1.18)$ & $1.00(0.91-1.11)$ & $0.85(0.71-1.02)$ \\
Lag 0-1 & $0.95(0.72-1.26)$ & $1.02(0.87-1.18)$ & $1.09(0.98-1.21)$ & $0.96(0.79-1.18)$ \\
Lag 0-2 & $0.98(0.73-1.33)$ & $1.03(0.87-1.21)$ & $1.14(1.01-1.27)^{*}$ & $1.05(0.85-1.31)$ \\
Lag 0-3 & $1.04(0.75-1.44)$ & $1.09(0.91-1.30)$ & $1.15(1.02-1.29)^{*}$ & $1.09(0.86-1.37)$ \\
Lag 0-4 & $1.07(0.76-1.51)$ & $1.16(0.96-1.41)$ & $1.13(0.99-1.29)$ & $1.10(0.86-1.40)$ \\
Lag 0-5 & $1.08(0.75-1.55)$ & $1.23(1.00-1.51)$ & $1.10(0.96-1.27)$ & $1.08(0.83-1.40)$ \\
Lag 0-6 & $1.08(0.73-1.59)$ & $1.27(1.02-1.58)^{*}$ & $1.07(0.92-1.23)$ & $1.05(0.80-1.38)$ \\
Lag 0-7 & $1.11(0.73-1.68)$ & $1.32(1.05-1.67)^{*}$ & $1.05(0.90-1.22)$ & $1.02(0.77-1.37)$ \\
Lag 0-14 & $0.80(0.44-1.45)$ & $1.26(0.90-1.77)$ & $0.91(0.73-1.12)$ & $0.59(0.39-0.88)^{*}$ \\
Lag 0-21 & $1.02(0.47-2.20)$ & $1.50(0.98-2.30)$ & $0.79(0.59-1.04)$ & $0.28(0.16-0.47)^{*}$ \\
Lag 0-28 & $1.46(0.54-3.96)$ & $1.61(0.91-2.82)$ & $0.79(0.54-1 / 16)$ & $0.24(0.12-0.50)^{*}$ \\
\hline
\end{tabular}

${ }^{*} p<0.05 . R R$ relative risk

temperature and AR outpatients among Asian population.

Many studies have found positive associations between hot temperatures and AR risk [34-37]. Similarly, reports showed that high temperatures were also associated with respiratory problems $[19,38]$. Zhang et al. found that increased levels of $\mathrm{SO}_{2}, \mathrm{NO}_{2}$, and $\mathrm{PM}_{10}$ increased a higher $\mathrm{AR}$ risk in the warm season than that in the cold season [39]. However, another study conducted in Finland indicated that respiratory symptoms including asthma and AR were increased in cold weather [34]. In this study, we found a significant positive association between AR and mild cold or mild hot temperatures, however, we did not find a significant association between AR and hot or cold temperatures. This may be due to behavioral and environmental changes in summer and winter, such as fewer outdoor activities and the use of air conditioners or central heating systems, reducing exposure to extreme temperatures. The differences between our current results and previous findings may be partially explained by differences in the region, climate, and temperature tolerance associated with the local population. Previous studies have found that populations at middle and low latitudes may adapt to high temperatures, and populations at high latitudes may adapt to low temperatures [40].

Other studies have demonstrated that ambient temperature can alter vegetation patterns spatially and temporally, and is associated with allergic symptoms in several ways [37, 41-43]. Pollen is a primary risk factor for AR. A study by Beggs indicated that changes in climate including increases in greenhouse gases $\left(\mathrm{CO}_{2}\right)$, may affect aeroallergens through plant distribution, pollen quantity, and season [44]. Evidence suggests that pollen grown at higher temperatures possesses significantly stronger allergenicity [45]. In addition, ambient temperature may also increase the risk of allergies by affecting the immune system since high temperature may promote increased levels of neutrophils [46, 47]. Neutrophils can release mediators, leading to bronchial epithelial damage and airway obstruction [46].

Another noteworthy finding from our study is the significant relationship between AR outpatient visits and mild cold temperatures at a lag of 0-7 days, and also between AR visits and mild hot temperatures at a lag of 0 3 days. One study conducted in Guangzhou, China, also found that the effects of warmer temperatures appeared immediately, whereas the effects of colder temperatures were delayed but persisted longer [48]. Warmer temperatures stimulate thermoregulation to maintain heat balance in the human body. During this process, increased heat dissipation is facilitated by accelerating blood circulation and increased sweating. In turn, these changes increase dehydration and salt loss, leading to increased blood viscosity and cholesterol levels, which can result in acute diseases attacks [49]. Warmer temperatures also stimulate plant growth, leading to more environmental allergens such as pollen, increasing the incidence of AR.

Stronger temperature effects on AR outpatient visits were observed in males than in females, at both mild hot and mild cold temperatures. One possible explanation is that males may have participated in more outdoor work resulting in greater exposure to higher temperatures. However, other studies have shown that females are more susceptible to temperature-related health hazards $[50,51]$. Clearly, further studies are required to investigate the specific underlying mechanisms for these effects.

Previous studies have observed that adverse effects of temperature on older adults and children are often 

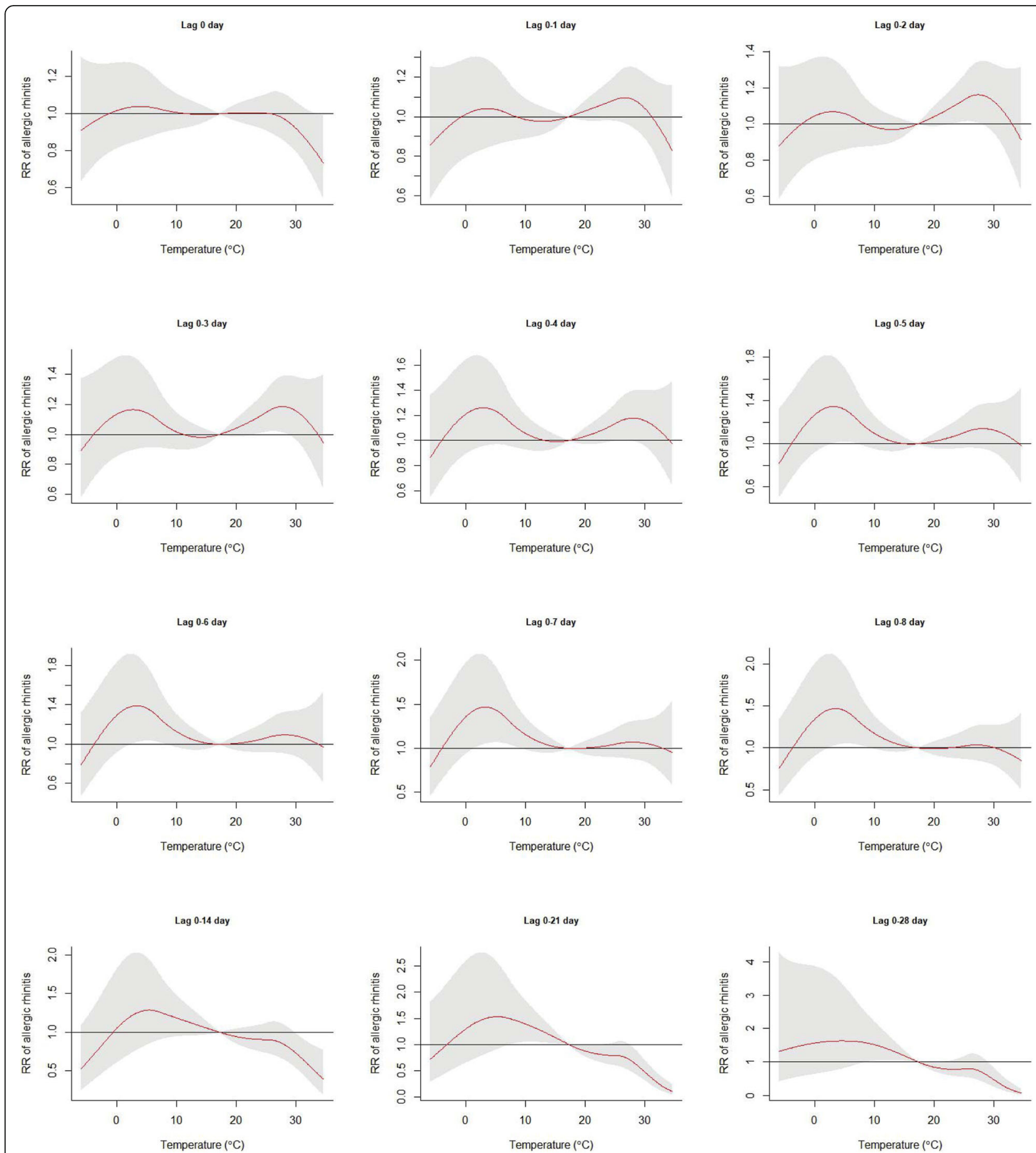

Fig. 1 Exposure-response curves of daily mean temperature and cumulative relative risk of daily allergic rhinitis (reference temperature at $17^{\circ} \mathrm{C}$ ) at different lag structures

higher than average [52]. Our study also observed a higher estimate for AR risk in the younger and older groups, however, the effects in older adults were nonsignificant. It is noteworthy that the daily outpatient number of the younger and older groups were very small, this might cause some instability to the result. Further studies are needed to elucidate reasons for this discrepancy.

Our findings will contribute to understanding the influence of ambient temperature on $\mathrm{AR}$, and to predict 


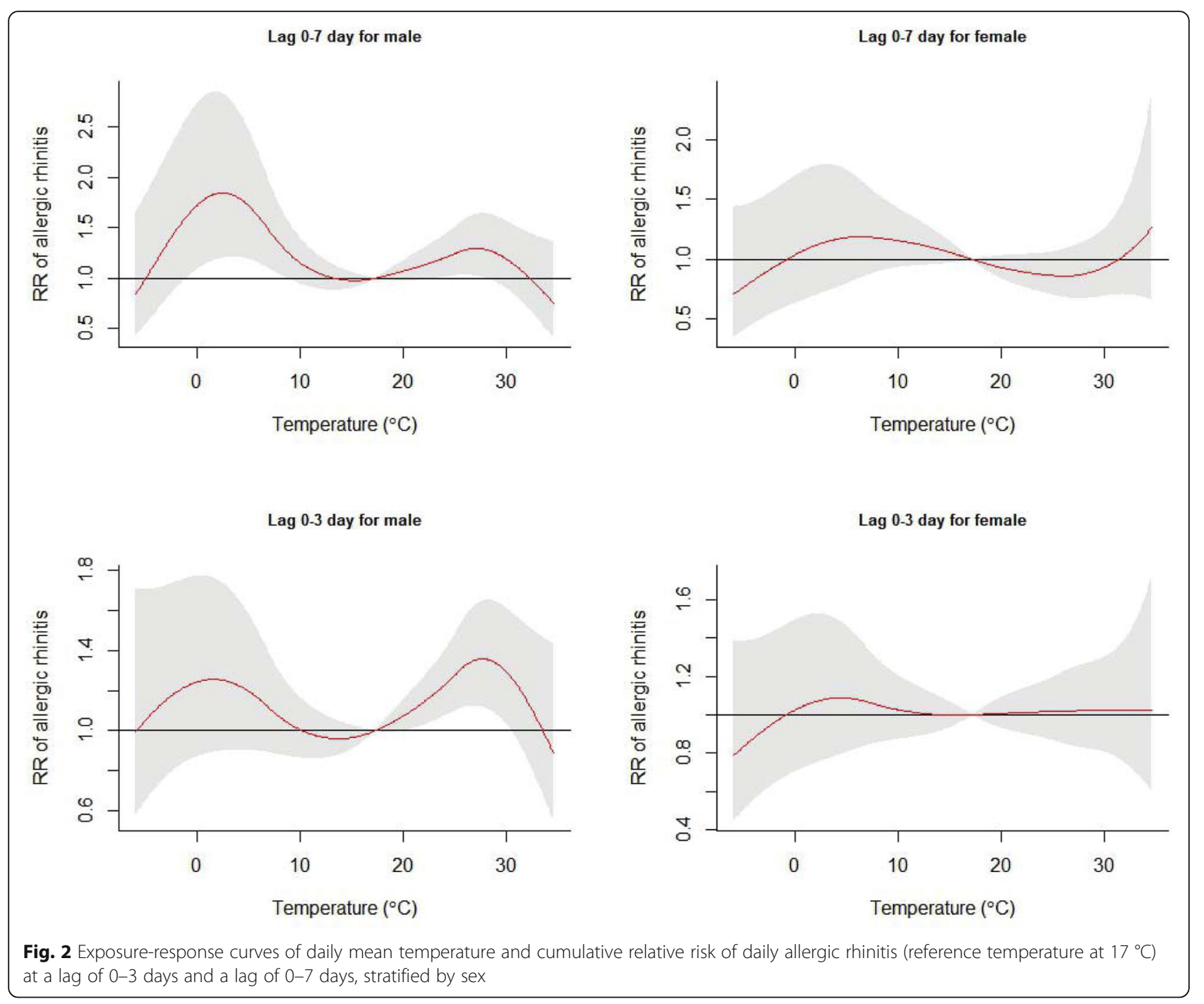

the impact of increased average temperatures due to climate change on the health of individuals with allergies. In addition, as global average temperatures and the incidence of allergies continue to increase, our results will provide a basis for future studies on the effects of increased temperature specifically on AR, and may also aid in the formulation of relevant health protection strategies.

Nevertheless, there are some limitations in our study. First, ecological bias was inevitable. For instance, outdoor fixed-site monitoring data were used as surrogates for individual temperature exposure levels, which may have caused measurement errors since individuals stay indoors most of the time [53]. Although the magnitude of the error is difficult to quantify, in general it would tend to bias the risk estimates downwards [54]. Second, individual lifestyles (such as the use of air conditioning and heating systems) would significantly alter the exposure temperature for a proportion of the population. Third, concentrations of several allergens related to AR (such as plant pollen) are significantly associated with temperature [55], and their spatial distribution may also differ significantly. Together, these factors may affect the magnitude of the calculated estimates. Fourth, daily outpatient number for the younger $(<15$ years) and the old ( $\geq 65$ years) were small, their results might be unrobust. Finally, this study gathered data from only one city, and therefore the general applicability of the results may be limited.

\section{Conclusions}

In summary, mild cold and mild hot temperatures both significantly increased the AR hospital outpatient visits in Xinxiang, China. This adverse effect was especially pronounced in males and in the younger population $(<$ 15 years of age). As the global average temperature 


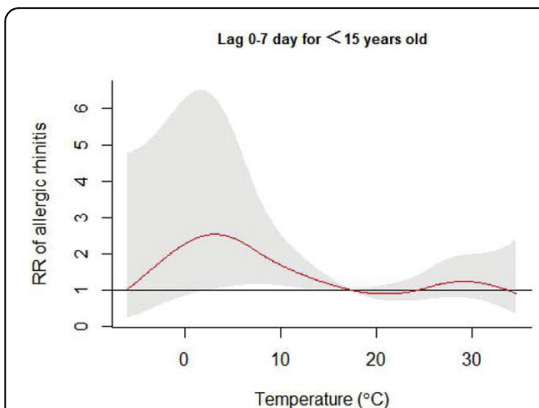

Lag 0.3 day for $<15$ years old

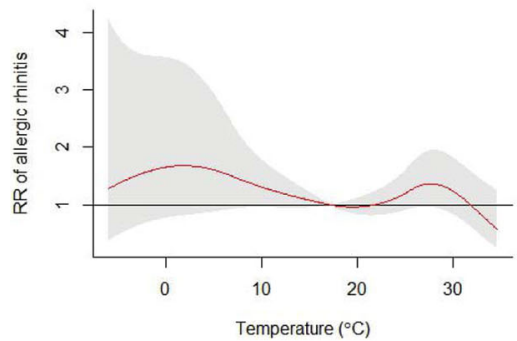

Lag 0.7 day for 15.64 years old

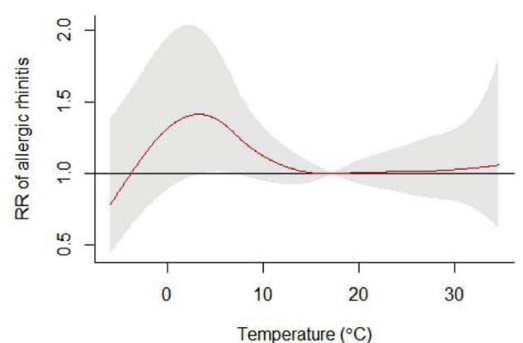

Lag 0-3 day for $15-64$ years old

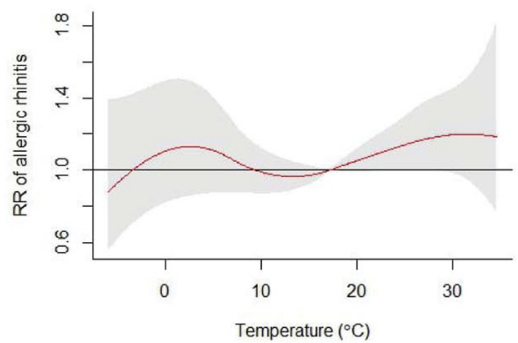

Lag 0.7 day for $\geq 65$ years old

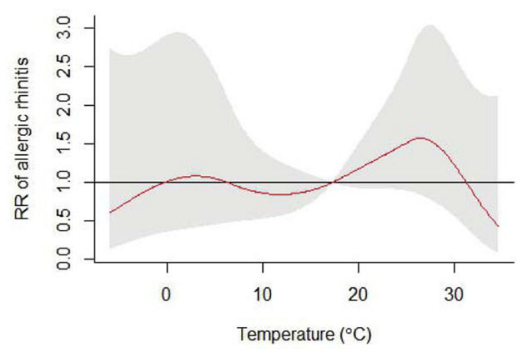

Lag 0.3 day for $\geq 65$ years old

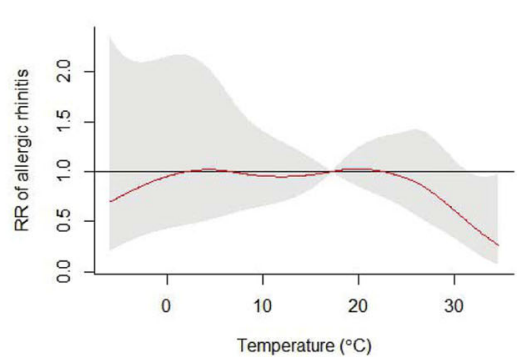

Fig. 3 Exposure-response curves of daily mean temperature and cumulative relative risk of daily allergic rhinitis (reference temperature at $17^{\circ} \mathrm{C}$ ) at a lag of 0-3 days and a lag of 0-7 days, stratified by age

increases, individuals with AR or other allergies may develop heat-related health problems. Our study may have important public health implications for controlling and preventing adverse health effects associated with exposure to increased air temperature.

\section{Supplementary Information}

The online version contains supplementary material available at https://doi. org/10.1186/s12889-021-10671-6.

Additional file 1: Figure S1. Relative risks of allergic rhinitis associated with daily mean temperature at 75 th percentile relative to median temperature at lag02 day using different degrees of freedom per year.

\section{Acknowledgements}

We are acknowledged the help of Xinxiang Central Hospital, Xinxiang First People's Hospital, Xinxiang Second People's Hospital, and the Third Affiliated Hospital of Xinxiang Medical University.

\section{Authors' contributions}

G.J. and L.M. Investigation, Methodology, Data curation, Validation, Visualization, Software, Formal analysis, writing - original draft. S.Y., W.J., and A.Z. Software, Validation, Visualization, Writing - review. L.Y. and L.J. Methodology, Data curation, Validation. J.Z. and W.W. Investigation, Methodology, Validation. S.J. Conceptualization, Funding acquisition, Supervision, Writing - review \& editing, Project administration, Resources, Validation. The authors read and approved the final manuscript.

\section{Funding}

The study was supported by the PhD Research Project of Xinxiang Medical University (XYBSKYZZ201804), Key Scientific Research Projects in Universities of Henan (19B330004) and Peak Subject Project of Public Health in Xinxiang Medical University.

\section{Availability of data and materials}

The datasets used and analyzed during the current study available from the corresponding author on reasonable request.

\section{Declarations}

Ethics approval and consent to participate

Not applicable. There were no human or animal experiments in this study.

Consent for publication

Not applicable.

\section{Competing interests}

The authors declare no competing interest.

\section{Author details}

${ }^{1}$ Xinxiang Medical University, Xinxiang 453003, China. ${ }^{2}$ Henan International Collaborative Laboratory for Health Effects and Intervention of Air Pollution, Xinxiang 453003, China. ${ }^{3}$ National Institute of Environmental Health, Chinese Center for Disease Control and Prevention, Beijing 100021, China. ${ }^{4}$ Xinxiang Central Hospital, Xinxiang 453001, China.

Received: 8 January 2021 Accepted: 17 March 2021

Published online: 27 March 2021

References

1. Bousquet J, Khaltaev N, Cruz AA, Denburg J, Fokkens WJ, Togias A, et al. Allergic rhinitis and its impact on asthma (ARIA) 2008 update (in collaboration with the World Health Organization, GA (2) LEN and AllerGen). Allergy. 2008;63(Suppl 86):8-160. https://doi.org/10.1111/j.1398-9995.2007.01 620.x

2. Brozek JL, Bousquet J, Agache I, Agarwal A, Bachert C, Bosnic-Anticevich S, et al. Allergic rhinitis and its impact on asthma (ARIA) guidelines-2016 revision. J Allergy Clin Immunol. 2017;140(4):950-8. https://doi.org/10.1016/j. jaci.2017.03.050

3. Bousquet J, Van Cauwenberge P, Khaltaev N, Aria Workshop G, World Health O. Allergic rhinitis and its impact on asthma. J Allergy Clin Immunol. 2001;108(5 Suppl):S147-334. https://doi.org/10.1067/mai.2001.118891. 
4. Small P, Keith PK, Kim H. Allergic rhinitis. Allergy Asthma Clin Immunol. 2018;14(Suppl 2):51. https://doi.org/10.1186/s13223-018-0280-7.

5. Tripathi A, Patterson R. Impact of allergic rhinitis treatment on quality of life. Pharmacoeconomics. 2001;19(9):891-9. https://doi.org/10.2165/00019053-2 00119090-00001.

6. Zhang $Y$, Zhang L. Prevalence of allergic rhinitis in China. Allerg Asthma Immunol Res. 2014;6(2):105-13. https://doi.org/10.4168/aair.2014.6.2.105.

7. Cingi C, Topuz B, Songu M, Kara CO, Ural A, Yaz A, et al. Prevalence of allergic rhinitis among the adult population in Turkey. Acta Otolaryngol. 2010;130(5):600-6. https://doi.org/10.3109/00016480903311880.

8. Sears MR, Burrows B, Herbison GP, Holdaway MD, Flannery EM. Atopy in childhood. II. Relationship to airway responsiveness, hay fever and asthma. Clin Exp Allergy. 1993;23(11):949-56. https://doi.org/10.1111/j.1365-2222.1 993.tb00280.x.

9. Hsu SP, Lin KN, Tan CT, Lee FP, Huang HM. Prenatal risk factors and occurrence of allergic rhinitis among elementary school children in an urban city. Int J Pediatr Otorhinolaryngol. 2009;73(6):807-10. https://doi. org/10.1016/j.jpporl.2009.02.023.

10. Lim FL, Hashim Z, Than LT, Md Said S, Hisham Hashim J, Norback D. Asthma, airway symptoms and rhinitis in Office Workers in Malaysia: associations with house dust mite (HDM) allergy, cat allergy and levels of house dust mite allergens in office dust. PLoS One. 2015;10(4):e0124905. https://doi.org/10.1371/journal.pone.0124905.

11. Thanaviratananich S, Cho SH, Ghoshal AG, Muttalif AR, Lin HC, Pothirat C, et al. Burden of respiratory disease in Thailand: results from the APBORD observational study. Medicine (Baltimore). 2016;95(28):e4090. https://doi. org/10.1097/MD.0000000000004090.

12. Kakli HA, Riley TD. Allergic rhinitis. Prim Care. 2016;43(3):465-75. https://doi org/10.1016/j.pop.2016.04.009.

13. Chong SN, Chew FT. Epidemiology of allergic rhinitis and associated risk factors in Asia. World Allergy Organ J. 2018;11(1):17. https://doi.org/10.1186/ s40413-018-0198-Z

14. Zhao Y, Huang Z, Wang S, Hu J, Xiao J, Li X, et al. Morbidity burden of respiratory diseases attributable to ambient temperature: a case study in a subtropical city in China. Environ Health. 2019;18(1):89. https://doi.org/10.11 86/s12940-019-0529-8.

15. Armstrong B, Sera F, Vicedo-Cabrera AM, Abrutzky R, Astrom DO, Bell ML, et al. The role of humidity in associations of high temperature with mortality: a multicountry, Multicity Study. Environ Health Perspect. 2019; 127(9):97007. https://doi.org/10.1289/EHP5430.

16. de' Donato FK, Leone M, Scortichini M, De Sario M, Katsouyanni K, Lanki T, et al. Changes in the Effect of Heat on Mortality in the Last 20 Years in Nine European Cities. Results from the PHASE Project. Int J Environ Res Public Health. 2015;12:15567-83.

17. Zhang Y, Peng L, Kan H, Xu J, Chen R, Liu Y, et al. Effects of meteorologica factors on daily hospital admissions for asthma in adults: a time-series analysis. PLoS One. 2014;9(7):e102475. https://doi.org/10.1371/journal.pone. 0102475.

18. Lin YK, Chang CK, Wang YC, Ho TJ. Acute and prolonged adverse effects of temperature on mortality from cardiovascular diseases. PLoS One. 2013; 8(12):e82678. https://doi.org/10.1371/journal.pone.0082678.

19. Voelker R. Asthma forecast: why heat, humidity trigger symptoms. JAMA. 2012;308(1):20. https://doi.org/10.1001/jama.2012.7533.

20. Williams R. Climate change blamed for rise in hay fever. Nature. 2005; 434(7037):1059. https://doi.org/10.1038/nature03682.

21. Hyrkas H, Ikaheimo TM, Jaakkola JJ, Jaakkola MS. Asthma control and cold weather-related respiratory symptoms. Respir Med. 2016;113:1-7. https://doi. org/10.1016/j.rmed.2016.02.005

22. Harju T, Makinen T, Nayha S, Laatikainen T, Jousilahti P, Hassi J. Cold-related respiratory symptoms in the general population. Clin Respir J. 2010;4(3):17685. https://doi.org/10.1111/j.1752-699X.2009.00172.x.

23. Piedrahita $\mathrm{H}, \mathrm{Oksa} J$, Malm C, Rintamaki $\mathrm{H}$. Health problems related to working in extreme cold conditions indoors. Int J Circumpolar Health. 2008; 67(2-3):279-87. https://doi.org/10.3402/ijch.v67i2-3.18286.

24. Koskela $\mathrm{OH}$. Cold air-provoked respiratory symptoms: the mechanisms and management. Int J Circumpolar Health. 2007;66(2):91-100. https://doi.org/1 0.3402/ijch.v66i2.18237

25. Wang J, Lu M, An Z, Jiang J, Li J, Wang Y, Du S, Zhang X, Zhou H, Cui J et al: Associations between air pollution and outpatient visits for allergic rhinitis in Xinxiang, China. Environmental Science and Pollution Research
2020, Associations between air pollution and outpatient visits for allergic rhinitis in Xinxiang, China.

26. Song J, Lu M, Zheng L, Liu Y, Xu P, Li Y, et al. Acute effects of ambient air pollution on outpatient children with respiratory diseases in Shijiazhuang, China. BMC Pulm Med. 2018;18(1):150. https://doi.org/10.1186/s12890-0180716-3.

27. Cui Y, Ai S, Liu Y, Qian ZM, Wang C, Sun J, et al. Hourly associations between ambient temperature and emergency ambulance calls in one central Chinese city: call for an immediate emergency plan. Sci Total Environ. 2020;711:135046. https://doi.org/10.1016/j.scitotenv.2019.135046.

28. Marinaccio A, Scortichini M, Gariazzo C, Leva A, Bonafede M, de' Donato FK, Stafoggia M, Viegi G, Michelozzi P, Group BC: Nationwide epidemiological study for estimating the effect of extreme outdoor temperature on occupational injuries in Italy. Environ Int 2019, 133(Pt A): 105176.

29. Alahmad B, Shakarchi A, Alseaidan M, Fox M. The effects of temperature on short-term mortality risk in Kuwait: a time-series analysis. Environ Res. 2019; 171:278-84. https://doi.org/10.1016/j.envres.2019.01.029.

30. Sherbakov T, Malig B, Guirguis K, Gershunov A, Basu R. Ambient temperature and added heat wave effects on hospitalizations in California from 1999 to 2009. Environ Res. 2018;160:83-90. https://doi.org/10.1016/j. envres.2017.08.052.

31. Gasparrini A, Armstrong B, Kenward MG. Distributed lag non-linear models. Stat Med. 2010;29(21):2224-34. https://doi.org/10.1002/sim.3940.

32. Ma W, Chen R, Kan H. Temperature-related mortality in 17 large Chinese cities: how heat and cold affect mortality in China. Environ Res. 2014;134; 127-33. https://doi.org/10.1016/j.envres.2014.07.007.

33. Zeka A, Zanobetti A, Schwartz J. Individual-level modifiers of the effects of particulate matter on daily mortality. Am J Epidemiol. 2006;163(9):849-59. https://doi.org/10.1093/eaje/kwj116.

34. Hyrkäs H, Jaakkola MS, Ikäheimo TM, Hugg TT, Jaakkola JJK. Asthma and allergic rhinitis increase respiratory symptoms in cold weather among young adults. Respir Med. 2014;108(1):63-70. https://doi.org/10.1016/j. rmed.2013.10.019.

35. Lam HCY, Chan EYY. Effects of high temperature on existing allergic symptoms and the effect modification of allergic history on health outcomes during hot days among adults: An exploratory cross-sectional telephone survey study. Environ Res. 2019;175:142-7. https://doi.org/10.101 6/j.envres.2019.05.017.

36. Genuneit J, Seibold AM, Apfelbacher CJ, Konstantinou GN, Koplin JJ, La Grutta S, et al. Task force 'Overview of systematic reviews in allergy epidemiology ' of the EIGoE: overview of systematic reviews in allergy epidemiology. Allergy. 2017;72(6):849-56. https://doi.org/10.1111/all.13123.

37. Reinmuth-Selzle K, Kampf CJ, Lucas K, Lang-Yona N, Frohlich-Nowoisky J, Shiraiwa $\mathrm{M}$, et al. Air pollution and climate change effects on allergies in the Anthropocene: abundance, interaction, and modification of allergens and adjuvants. Environ Sci Technol. 2017;51(8):4119-41. https://doi.org/10.1 021/acs.est.6b04908.

38. Hayes D Jr, Collins PB, Khosravi M, Lin RL, Lee LY. Bronchoconstriction triggered by breathing hot humid air in patients with asthma: role of cholinergic reflex. Am J Respir Crit Care Med. 2012;185(11):1190-6. https:// doi.org/10.1164/rccm.201201-00880C.

39. Zhang F, Krafft T, Ye B, Zhang F, Zhang J, Luo H, et al. The lag effects and seasonal differences of air pollutants on allergic rhinitis in Beijing. Sci Total Environ. 2013;442:172-6. https://doi.org/10.1016/j.scitotenv.2012.09.039.

40. Hu MJ, Ma WJ, Zhang YH, Liu T, Lin HL, Luo Y, et al. Relationship between temperature and the risks of mortality in China: a meta-analysis. Zhonghua Liu Xing Bing Xue Za Zhi. 2013;34(9):922-6.

41. Shea KM, Truckner RT, Weber RW, Peden DB. Climate change and allergic disease. J Allergy Clin Immunol. 2008;122(3):443-53; quiz 454-445. https:// doi.org/10.1016/j.jaci.2008.06.032.

42. Bielory L, Lyons K, Goldberg R. Climate change and allergic disease. Curr Allergy Asthma Rep. 2012;12(6):485-94. https://doi.org/10.1007/s11882-0120314-z.

43. Demain JG. Climate change and the impact on respiratory and allergic disease: 2018. Curr Allergy Asthma Rep. 2018;18(4):22. https://doi.org/10.1 007/s11882-018-0777-7.

44. Beggs PJ. Impacts of climate change on aeroallergens: past and future. Clin Exp Allergy. 2004;34(10):1507-13. https://doi.org/10.1111/j.1365-2222.2004.02 061.x.

45. Ahlholm JU, Helander ML, Savolainen J. Genetic and environmental factors affecting the allergenicity of birch (Betula pubescens ssp. czerepanovii [Orl.] 
Hamet-ahti) pollen. Clin Exp Allergy. 1998;28(11):1384-8. https://doi.org/10.1 046/j.1365-2222.1998.00404.x.

46. Sampson AP. The role of eosinophils and neutrophils in inflammation. Clin Exp Allergy. 2000;30(Suppl 1):22-7. https://doi.org/10.1046/j.1365-2222.2000. 00092.x.

47. LaVoy EC, McFarlin BK, Simpson RJ. Immune responses to exercising in a cold environment. Wilderness Environ Med. 2011;22(4):343-51. https://doi. org/10.1016/j.wem.2011.08.005.

48. Yang J, Ou CQ, Guo Y, Li L, Guo C, Chen PY, et al. The burden of ambient temperature on years of life lost in Guangzhou, China. Sci Rep. 2015;5(1): 12250. https://doi.org/10.1038/srep12250.

49. Keatinge WR, Coleshaw SR, Easton JC, Cotter F, Mattock MB, Chelliah R. Increased platelet and red cell counts, blood viscosity, and plasma cholesterol levels during heat stress, and mortality from coronary and cerebral thrombosis. Am J Med. 1986;81(5):795-800. https://doi.org/10.1016/ 0002-9343(86)90348-7.

50. Zhang Y, Yan C, Kan H, Cao J, Peng L, Xu J, et al. Effect of ambient temperature on emergency department visits in Shanghai, China: a time series study. Environ Health. 2014;13:100.

51. Yang J, Liu HZ, Ou CQ, Lin GZ, Zhou Q, Shen GC, et al. Global climate change: impact of diurnal temperature range on mortality in Guangzhou, China. Environ Pollut. 2013;175:131-6. https://doi.org/10.1016/j.envpol.2 012.12.021.

52. Cheng J, Xu Z, Zhu R, Wang X, Jin L, Song J, et al. Impact of diurnal temperature range on human health: a systematic review. Int J Biometeorol. 2014;58(9):2011-24. https://doi.org/10.1007/s00484-014-0797-5.

53. Niu Y, Chen R, Liu C, Ran P, Chen A, Chen X, Kan H: The association between ambient temperature and out-of-hospital cardiac arrest in Guangzhou, China. Sci Total Environ 2016, 572(dec.1): 114-118.

54. Zeger SL, Thomas D, Dominici F, Samet JM, Schwartz J, Dockery D, et al. Exposure measurement error in time-series studies of air pollution: concepts and consequences. Environ Health Perspect. 2000;108(5):419-26. https://doi. org/10.1289/ehp.00108419.

55. Samitas K, Carter A, Kariyawasam HH, Xanthou G. Upper and lower airway remodelling mechanisms in asthma, allergic rhinitis and chronic rhinosinusitis: the one airway concept revisited. Allergy. 2018;73(5):9931002. https://doi.org/10.1111/all.13373

\section{Publisher's Note}

Springer Nature remains neutral with regard to jurisdictional claims in published maps and institutional affiliations.

Ready to submit your research? Choose BMC and benefit from:

- fast, convenient online submission

- thorough peer review by experienced researchers in your field

- rapid publication on acceptance

- support for research data, including large and complex data types

- gold Open Access which fosters wider collaboration and increased citations

- maximum visibility for your research: over $100 \mathrm{M}$ website views per year

At $\mathrm{BMC}$, research is always in progress.

Learn more biomedcentral.com/submissions 